\title{
Immunoglobulin G4-related sclerosing disease involving the mandible
}

Antonio CK Tong ${ }^{1,2}$ *, PhD, BDS, Irene OL Ng ${ }^{3}$, PhD, MD, Miko CM Lo², MOMS RCSEd, BDS

\author{
${ }^{1}$ Queen Mary Hospital, Pokfulam, Hong Kong \\ ${ }^{2}$ Department of Health, Hong Kong \\ ${ }^{3}$ Department of Pathology and State Key Laboratory for Liver Research, The University of Hong Kong, Pokfulam, Hong Kong \\ *Corresponding author: antonio.tong@gmail.com
}

Hong Kong Med J 2017;23:534-6

DOI: 10.12809/hkmj154733

\section{Case report}

A 46-year-old female was referred by her general dental practitioner in December 2013 for investigation of delayed healing of lower right premolar $(44,45)$ socket wounds following tooth extraction 3 weeks earlier. The lower right first and second premolars-teeth 44, 45-had presented with sudden onset of pain and rapid increase in mobility over a 2-month period. Both teeth were subsequently extracted but the patient experienced increasing pain and discomfort around the extraction sites.

Clinical examination showed unhealed sockets of teeth 44, 45; with associated flabby, oedematous and verrucous gingival tissue (Fig 1). The lower right canine tooth demonstrated grade III mobility with radiographic evidence of periodontal bone loss. The provisional diagnoses included eosinophilic granuloma or Langerhans cell histiocytosis, massive osteolysis, and malignancies. Incisional biopsy was performed under local anaesthesia. Histopathological examination revealed infiltration by chronic inflammatory cells involving the epithelium and stroma, with absence of malignancy.

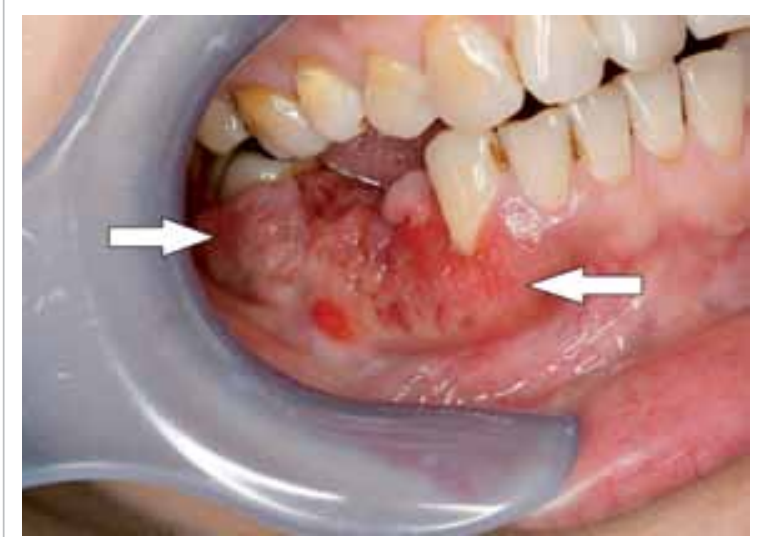

FIG I. Immunoglobulin G4-related disease involvement of right mandibular molar region

Note the clinical appearance of verrucous, oedematous lesion involving lower right molar gingival and alveolar muscosal tissues (arrows)
The symptoms persisted after the biopsy, with progression of periodontal bone loss around the lower right canine. A repeated biopsy was performed. Tissue was taken from the gingival mucosa, the soft tissue around the previous extraction sockets, and the involved mandibular bone.

Histologically, the soft tissue surrounding the involved area comprised heavily inflamed fibrous tissue that was denuded without epithelial covering. It contained a heavy infiltrate of lymphocytes and plasma cells with some polymorphs. The plasma cells were normal in appearance. The fibrous background was composed of whorls of relatively plump fibroblasts in interlacing fascicles (Fig 2a). Frequent prominent arteries were seen but no definite phlebitis was evident (Fig 2b). Granulomas were absent and a special stain for fungal organisms was negative. There was no evidence of malignancy. With immunohistochemistry, immunoglobulin (Ig) G4positive cells constituted an average of 60 cells per high-power field (magnification, $\mathrm{x} 40$ ) and the ratio of IgG4:IgG positive cells was more than $40 \%$ (Figs $2 \mathrm{c}$ and 2d). The predominance of IgG4-positive cells in the lesions excluded ordinary chronic inflammatory changes. Immunostains for dendritic cell markers (CD1a and CR2) and S-100 proteins were negative, ruling out Langerhans cell histiocytosis. The bone specimen showed a moderate infiltrate of plasma cells and lymphocytes, with some polymorphs in the marrow spaces. Immunostaining of the bone specimen showed a range of 12 to 27 IgG4-positive cells per high-power field. The overall features were suggestive of IgG4-related disease (IgG4-RD).

Complete blood picture, and liver and renal function tests were all normal. Serum IgG4 level was within the normal range. Her IgG level was 1410 $\mathrm{mg} / \mathrm{dL}$ (reference range, 919-1725 mg/dL), IgA 272 $\mathrm{mg} / \mathrm{dL}(70-386 \mathrm{mg} / \mathrm{dL})$, IgM $162 \mathrm{mg} / \mathrm{dL}$ (55-307 $\mathrm{mg} / \mathrm{dL})$, and IgG4 $0.88 \mathrm{~g} / \mathrm{L}(0.030-2.0 \mathrm{~g} / \mathrm{L})$. Systemic involvement of IgG4-RD was not evident on clinical examination or positron emission tomographycomputed tomography (PET-CT) from skull base to thighs. Systemic steroid treatment was commenced with dexamethasone $8 \mathrm{mg}$ daily. The patient reported 


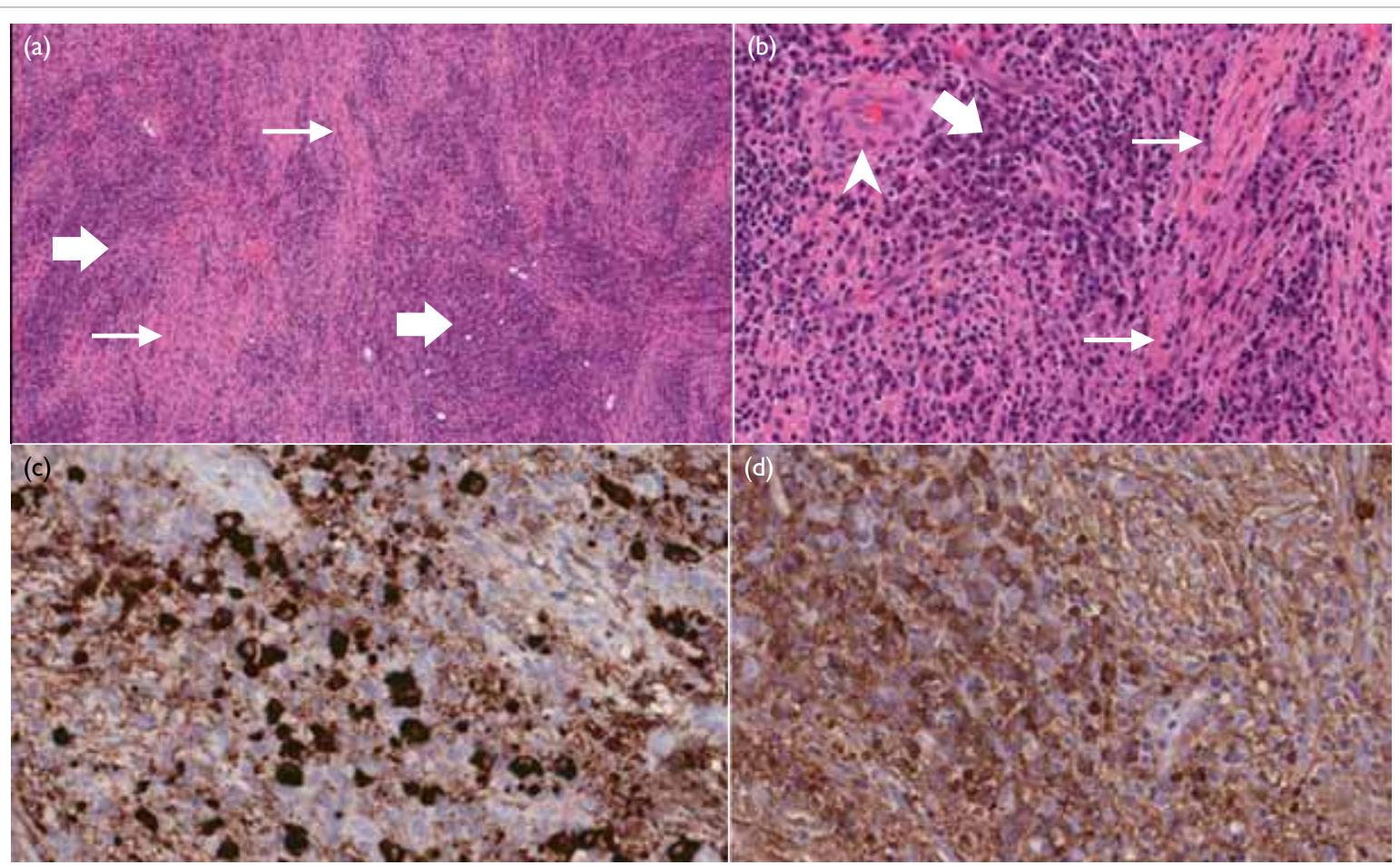

FIG 2. Histological and immunohistochemical findings

(a) The soft tissues surrounding the involved area consist of heavily inflamed fibrous tissue which contains a heavy infiltrate of lymphocytes and plasma cells (thick arrows) [H\&E; original magnification, $\times 4$ ]. The fibrous background is composed of whorls of relatively plump fibroblasts in interlacing fascicles (thin arrows). (b) High-power view of the fibrous background with relatively plump fibroblasts in interlacing fascicles (thin arrows) and the heavy infiltrate of plasma cells (thick arrow); frequent prominent arteries (arrowhead) are seen (H\&E; original magnification, $\times 20$ ). (c) Immunostain for lgG4: immunochemistry shows that lgG4 cells constituted on average 60 cells per high-power field (original magnification, $\times 40$ ). (d) Immunostain for IgG: the ratio of $\operatorname{lgG} 4+/ \operatorname{lgG}+$ cells is more than $40 \%$ (original magnification, $\times 40$ )

Abbreviation: $\lg =$ immunoglobulin

symptomatic improvements 1 week after steroid treatment. Mobility of the lower right canine tooth decreased and returned to normal 3 weeks after steroid treatment.

The patient was also referred to a rheumatologist. Systemic involvement of IgG4 was not found. Four weeks after initiation of steroid medication, dexamethasone was replaced with prednisolone $40 \mathrm{mg}$ daily and maintained for another 4 weeks. After 8 weeks of systemic steroid administration, the dosage of prednisolone was reduced by $5 \mathrm{mg}$ each week. Concurrently, azathioprine $25 \mathrm{mg}$ per day was added with increments of $25 \mathrm{mg}$ per week to reach a dosage of $100 \mathrm{mg}$ per day. Eight months after initiation of medical treatment, the patient was maintained on azathioprine $100 \mathrm{mg}$ per day and prednisolone $5 \mathrm{mg}$ on alternate days. There was no evidence of recurrent clinical signs or symptoms 18 months after initiation of medical treatment.

\section{Discussion}

The IgG4-RD, also called IgG4-related sclerosing disease, is a newly recognised clinicopathological entity characterised by intense fibrosis and lymphoplasmacytic infiltration of involved tissues. ${ }^{1}$ The lesions show increased numbers of IgG4-positive plasma cells and are usually associated with a raised serum IgG4 level. Classically, IgG4-RD involves the pancreas, hepatobiliary tract, major salivary glands (including the lacrimal glands), lymph nodes, orbit, and lungs.

In the maxillofacial region, IgG4-RD usually involves the salivary, lacrimal, and pituitary glands. In the recent literature, it has also been reported to involve the nasal cavity, tongue, palatine tonsil, and hard palate. ${ }^{2}$ To the best of our knowledge, IgG4-RD has not been reported in the tooth-bearing region of the maxilla or the mandible. Characteristic organ involvement, elevated serum IgG4 levels, typical histopathology, and immunohistochemistry are supportive of a diagnosis of IgG4-RD. Criteria for the diagnosis of IgG4-RD in various organs have been proposed by Umehara et $\mathrm{al}^{3}$ and are summarised in the Box.

Interestingly, the present case had a normal 
BOX. Criteria for the diagnosis of immunoglobulin G4-related disease (IgG4-RD) in various organs ${ }^{3}$

(1) Clinical examination showing characteristic diffuse/localised swelling or masses in single or multiple organs;

(2) Haematological examination shows elevated serum lgG4 concentrations ( $\geq 135 \mathrm{mg} / \mathrm{dL})$; and

(3) Histopathological examination showing

(a) marked lymphocyte and plasma cell infiltration and fibrosis; and

(b) infiltration of lgG4+ plasma cells: ratio of $\operatorname{lgG} 4+/ \operatorname{lgG}+$ cells $>40 \%$ and $>10$ lgG4+ plasma cells/high-power field.

Diagnosis of IgG4-RD:

- Definite: criteria $(1)+(2)+(3)$

- Probable: criteria (1) + (3)

- Possible: criteria (1) + (2)

serum IgG4 level. In a previous retrospective analysis of 12 cases of IgG4-RD in Hong Kong, eight showed raised serum IgG4 levels. ${ }^{4}$ The pancreas, biliary tract, cervical lymph nodes, and salivary glands were the involved sites. None of the cases involved the oral cavity.

There is no consensus or approved treatment for IgG4-RD. Corticosteroids are the mainstay of therapy. Of note, PET-CT may be useful in defining disease extent and organ involvement more accurately. There are no prospective data to support the starting dose, tapering regimen, or duration of steroid treatment.

Khurram et $\mathrm{al}^{5}$ used a regimen of dexamethasone $10 \mathrm{mg}$ daily that was reduced to $6 \mathrm{mg}$ after a week. Dexamethasone was then replaced by prednisolone $5 \mathrm{mg}$ for a month followed by hydrocortisone pellets for maintenance. The Japanese strategy consists of treatment with prednisolone $(0.6 \mathrm{mg} / \mathrm{kg})$ for 2 to 4 weeks, tapered over 3 to 6 months to $5 \mathrm{mg}$ daily. This is followed by maintenance therapy with 2.5 to $5 \mathrm{mg}$ steroids for 6 months to 3 years. Remission rates are higher than $95 \%$.

Serum IgG4 levels are not reliable for monitoring therapy response or predicting disease relapse, and may not be raised in IgG4-RD. Raised serum IgG4 levels can remain elevated in over half of patients following treatment. Most relapses occur in the first 3 years following diagnosis and are steroidresponsive. Relapses can involve different organs to those at the initial presentation. ${ }^{6}$

\section{References}

1. Cheuk W, Chan JK. IgG4-related sclerosing disease: a critical appraisal of an evolving clinicopathologic entity. Adv Anat Pathol 2010;17:303-32.

2. Andrew N, Kearney D, Sladden N, Goss A, Selva D. Immunoglobulin G4-related disease of the hard palate. J Oral Maxillofac Surg 2014;72:717-23.

3. Umehara H, Okazaki K, Masaki Y, et al. Comprehensive diagnostic criteria for IgG4-related disease (IgG4-RD), 2011. Mod Rheumatol 2012;22:21-30.

4. Ng TL, Leong IS, Tang WL, et al. Immunoglobulin G4related sclerosing disease: experience with this novel entity in a local hospital. Hong Kong Med J 2011;17:280-5.

5. Khurram SA, Fernando M, Smith AT, Hunter KD. IgG4related sclerosing disease clinically mimicking oral squamous cell carcinoma. Oral Surg Oral Med Oral Pathol Oral Radiol 2013;115:e48-51.

6. Kamisawa T, Okazaki K, Kawa S, Shimosegawa T, Tanaka M; Research Committee for Intractable Pancreatic Disease and Japan Pancreas Society. Japanese consensus guidelines for management of autoimmune pancreatitis: III. Treatment and prognosis of AIP. J Gastroenterol 2010;45:471-7. 